\title{
Chromosome hydroxymethylation patterns in human zygotes and cleavage-stage embryos
}

\author{
Olga A Efimova ${ }^{1,2}$, Anna A Pendina ${ }^{1,2,3}$, Andrei V Tikhonov ${ }^{1,2,3}$, Irina D Fedorova ${ }^{1}$, \\ Mikhail I Krapivin², Olga G Chiryaeva ${ }^{1,4,5}$, Evgeniia M Shilnikova ${ }^{1,2}$, Mariia A Bogdanova ${ }^{1,6}$, \\ Igor Yu Kogan ${ }^{1,7}$, Tatyana V Kuznetzova ${ }^{1,2}$, Alexander M Gzgzyan ${ }^{1,2}$, Edward K Ailamazyan 1,2,7 \\ and Vladislav S Baranov ${ }^{1,2,5}$
}

${ }^{1}$ D.O. Ott Research Institute of Obstetrics and Gynecology, Mendeleevskaya line, 3, 199034 St Petersburg, Russia,

${ }^{2}$ St Petersburg State University, Universitetskaya nab.7/9, 199034 St Petersburg, Russia, ${ }^{3}$ Center for Medical Genetics, Tobolskaya ul., 5, 194044 St Petersburg, Russia, ${ }^{4}$ St Petersburg State Pediatric Medical University, Litovskaya ul., 2, 194100 St Petersburg, Russia, ${ }^{5}$ S.M. Kirov Military Medical Academy, Lebedeva ul., 6, 194044 St Petersburg, Russia, ${ }^{6}$ N.I. Pirogov National Medical-Surgery Center, St Petersburg Clinic Complex, nab. Fontanki, 154, 190103 St Petersburg, Russia and ${ }^{7}$ I.P. Pavlov First St Petersburg State Medical University, L'va Tolstogo ul., 6/8, 197022 St Petersburg, Russia

Correspondence should be addressed to O A Efimova; Email: efimova_o82@mail.ru

\begin{abstract}
We report the sequential changes in 5 -hydroxymethylcytosine $(5 \mathrm{hmC})$ patterns in the genome of human preimplantation embryos during DNA methylation reprogramming. We have studied chromosome hydroxymethylation and methylation patterns in triploid zygotes and blastomeres of cleavage-stage embryos. Using indirect immunofluorescence, we have analyzed the localization of $5 \mathrm{hmC}$ and its co-distribution with 5-methylcytosine $(5 \mathrm{mC})$ on the QFH-banded metaphase chromosomes. In zygotes, $5 \mathrm{hmC}$ accumulates in both parental chromosome sets, but hydroxymethylation is more intensive in the poorly methylated paternal set. In the maternal set, chromosomes are highly methylated, but contain little $5 \mathrm{hmC}$. Hydroxymethylation is highly region specific in both parental chromosome sets: hydroxymethylated loci correspond to R-bands, but not G-bands, and have well-defined borders, which coincide with the R/G-band boundaries. The centromeric regions and heterochromatin at 1q12, 9q12, 16q11.2, and Yq12 contain little $5 \mathrm{mC}$ and no $5 \mathrm{hmC}$. We hypothesize that $5 \mathrm{hmC}$ may mark structural/functional genome 'units' corresponding to chromosome bands in the newly formed zygotic genome. In addition, we suggest that the hydroxymethylation of R-bands in zygotes can be treated as a new characteristic distinguishing them from G-bands. At cleavages, chromosomes with asymmetrical hydroxymethylation of sister chromatids appear. They decrease in number during cleavages, whereas totally non-hydroxymethylated chromosomes become numerous. Taken together, our findings suggest that, in the zygotic genome, $5 \mathrm{hmC}$ is distributed selectively and its pattern is determined by both parental origin of chromosomes and type of chromosome bands - R, G, or C. At cleavages, chromosome hydroxymethylation pattern is dynamically changed due to passive and non-selective overall loss of $5 \mathrm{hmC}$, which coincides with that of $5 \mathrm{mC}$.
\end{abstract}

Reproduction (2015) 149 223-233

\section{Introduction}

Genome-wide epigenetic reprogramming is a crucial process in mammalian preimplantation development. A major aspect of this process is the establishment of specific DNA methylation patterns (5-methylcytosine, $5 \mathrm{mC}$ ) through demethylation - decrease in DNA methylation level - and subsequent remethylation (Monk et al. 1987, Kafri et al. 1992, Santos et al. 2002). The reprogramming of DNA methylation is required to obtain developmental competence, including the onset of pluripotency and correct lineage commitment (Reik et al. 2001, Patkin 2002, Surani et al. 2007).
In postimplantation development, the patterns of $5 \mathrm{mC}$ are established in a tissue-specific manner and are characterized by a relative stability and high heritability (Bird 2002, Byun et al. 2009, Tolmacheva et al. 2011, Bonder et al. 2014). The correct DNA methylation patterns provide regulation of cell type-specific gene expression by affecting the capacity of DNA to interact with transcription factors and methyl-CpG-binding proteins (Doerfler 1981, Razin \& Cedar 1991, Zou et al. 2012). Numerous studies discuss the possible role of the altered DNA methylation patterns in the initiation and progression of various pathologies, including developmental failures (Shi \& Haaf 2002, 
Pliushch et al. 2010, Ehrlich \& Lacey 2013, Shubina et al. 2013, Skryabin et al. 2013, Zheleznyakova et al. 2013, Luo et al. 2014, Pendina et al. 2014).

In mammalian preimplantation development, DNA demethylation involves two mechanisms: replicationindependent (active) and replication-dependent (passive) loss of 5mC (Kafri et al. 1993, Mayer et al. 2000). Until recently, the mechanisms of the active DNA demethylation remained unclear. The discovery of TET-mediated oxidation of $5 \mathrm{mC}$ suggested that the oxidation product 5 -hydroxymethylcytosine $(5 \mathrm{hmC})$ - is an intermediate in the active DNA demethylation (Tahiliani et al. 2009, Ito et al. 2010). The involvement of $5 \mathrm{hmC}$ in the DNA methylation reprogramming thus far has been demonstrated in mouse, rabbit, bovine, and porcine preimplantation embryos (Inoue \& Zhang 2011, Iqbal et al. 2011, Wossidlo et al. 2011, Salvaing et al. 2012, Zhang et al. 2012, Cao et al. 2014, Wang et al. 2014). Relevant data in human have not been obtained yet. It is known that the dynamic changes in $5 \mathrm{mC}$ patterns during embryonic cleavages are species specific (for a review see Abdalla et al. (2009)). Therefore, it could be expected that patterns of $5 \mathrm{hmC}-$ an oxidative derivative of $5 \mathrm{mC}-$ in the genome of human preimplantation embryos differ from those described in other mammalian species.

$5 \mathrm{hmC}$ is present in adult tissues at tissue-specific and quite constant levels (Li \& Liu 2011, Nestor et al. 2012, Ivanov et al. 2013) and shows association with gene regulatory elements and gene bodies (Stroud et al. 2011, Wu et al. 2011). 5hmC is selectively recognized by transcription factors (Yildirim et al. 2011, Zhenilo et al. 2013, Teif et al. 2014) and its level correlates with gene expression (Wu et al. 2011). These data advocate for the own function of $5 \mathrm{hmC}$ in the regulation of gene activity (Branco et al. 2011). Thus, during human preimplantation development - in the period of genome reorganization for totipotency with the subsequent lineage commitment - the changes in $5 \mathrm{hmC}$ patterns can be associated with regulation of the embryonic genome activity and alternatively, or complementarily, with the involvement of $5 \mathrm{hmC}$ in global genome reprogramming through oxidation of the $5 \mathrm{mC}$ pathway.

In this study, we address the following questions concerning the epigenetic reprogramming in human preimplantation development: i) whether $5 \mathrm{hmC}$ patterns undergo changes during DNA methylation reprogramming; ii) whether $5 \mathrm{hmC}$ patterns differ between parental genomes; iii) whether $5 \mathrm{hmC}$ patterns differ between euchromatic and heterochromatic genome regions; and iv) whether $5 \mathrm{hmC}$ is maintained throughout cleavage divisions. A promising experimental approach is the immunofluorescent analysis of $5 \mathrm{hmC}$ patterns on metaphase chromosomes. In contrast to interphase studies, it provides information on how whole and individual parental chromosomes and chromosome regions are hydroxymethylated. This seems to be of substantial scientific value, as genome loci possess different functions and are not uniformly structured and regulated (Craig \& Bickmore 1994, Gilbert et al. 2004, Zhu et al. 2013). The obtained data provide new insights into both the timing and the genome patterning of $5 \mathrm{hmC}$ in human preimplantation embryos.

\section{Materials and methods}

\section{Collection of human zygotes, cleavage-stage embryos, sperm, and oocytes}

The study included only triploid human zygotes and embryos, unsuitable for transfer or for cryopreservation, as normal ones were not available. Zygotes were produced by conventional IVF. Cleavage-stage embryos were produced by the cultivation of tripronucleate zygotes in the ISM1 medium (Origio, 10500060, Måløv, Denmark) until 4-8-cell stage and then in the BlastAssist medium (Origio, 12160010) until blastocyst stage under standard conditions. A total of 81 preimplantation embryos were included in the study: 20 zygotes, four embryos at the 3 -cell stage, five embryos at the 4-5-cell stage, 15 embryos at the 7-cell-morula stage, and 37 blastocysts.

Oocytes were aspirated from patients' follicles after hormone stimulation in the IVF cycles. Oocytes were rinsed in Flushing Medium (Origio, 10845060) prewarmed to $37^{\circ} \mathrm{C}$. Then, oocytes were incubated in the ISM1 medium (Origio, 10500060) at $37^{\circ} \mathrm{C}$ in an atmosphere of $5 \% \mathrm{CO}_{2}$. After $3 \mathrm{~h}$, routinely prepared sperm was added for IVF. To identify fertilization status, the presence of pronuclei was examined after $20 \mathrm{~h}$. Unfertilized oocytes were selected for the study. A total of 19 oocytes were included in the study.

Semen samples were obtained from sperm donors by masturbation after a 3 to 5 day abstinence period. A regular semen analysis (volume, $\mathrm{pH}$, concentration, motility, vitality, and morphology) was performed. The semen samples were split into aliquots and one $1 \mathrm{ml}$ aliquot from each sample was selected for the study. A total of five samples were included in the study with 100 spermatozoa analyzed in each sample.

All the biological samples were obtained at the Department of Assisted Reproductive Technologies, D.O. Ott Research Institute of Obstetrics and Gynecology (St Petersburg, Russia). This study was approved by the Institutional Review Board of D.O. Ott Research Institute of Obstetrics and Gynecology. All the samples were donated for research with the written informed consent obtained from patients. The study was conducted in accordance with the Declaration of Helsinki.

\section{Slide preparation and immunodetection of $5 \mathrm{hmC}$ and $5 \mathrm{mC}$}

For sperm preparations, $1 \mathrm{ml}$ aliquots of native semen samples were placed in $10 \mathrm{ml}$ of hypotonic solution $(0.9 \%$ sodium citrate). After $20 \mathrm{~min}$ of incubation at room temperature, hypotonic solution was replaced with $10 \mathrm{ml}$ of freshly prepared fixative (ethanol:glacial acetic acid, 3:1). The semen samples were fixed at $4{ }^{\circ} \mathrm{C}$ and the fixative was changed at least twice during a $60 \mathrm{~min}$ fixation period. The suspension was centrifuged for $10 \mathrm{~min}$ at $190 \mathrm{~g}$ and the supernatant was discharged leaving $0.5-1 \mathrm{ml}$ over the precipitate. The 
suspension was then dropped onto slides. The slides were air dried at room temperature.

Chromosome preparations from oocytes, zygotes, and cleaving embryos were made as described previously (Pendina et al. 2011). To obtain chromosome banding, the slides were stained with Hoechst 33258 and counterstained with actinomycin D (QFH/AcD technique), according to the protocol used previously (Grigorian et al. 2010). After photoimaging of QFH/AcD-stained metaphases, the slides were washed in distilled water, dehydrated in an ethanol series (70,80, and $96 \%$ ), and air dried.

The immunodetection of $5 \mathrm{hmC}$ and $5 \mathrm{mC}$ was performed according to the protocol used previously (Pendina et al. 2011). For DNA denaturation, the preparations of sperm were exposed to $2 \mathrm{M} \mathrm{HCl}$ for 20-40 min and the preparations of oocytes, zygotes, and cleaving embryos for 15-20 min at room temperature. Then, the slides were washed thoroughly in ice-cold PBS and distilled water. The slides were incubated with blocking solution (1\% BSA, 0.1\% Tween 20 in PBS) for $30-40 \mathrm{~min}$ at $37^{\circ} \mathrm{C}$ in a humidified chamber. Then, the mixture of antibodies against $5 \mathrm{hmC}$ (rabbit polyclonal, Active Motif, 39769, Carlsbad, CA, USA) and 5mC (mouse monoclonal, Eurogentec, BI-MECY-0100, Seraing, Belgium) diluted in blocking solution (1:500) was applied to the slides for $90 \mathrm{~min}$ at room temperature in the humidified chamber. The slides were washed thrice with PBS for 15 min each, supplemented with $0.5 \%$ Tween 20 at $43{ }^{\circ} \mathrm{C}$ in a shaking bath. The primary antibodies were detected by goat anti-rabbit Alexa Fluor 488 (Life Technologies, A-11008) and goat anti-mouse Alexa Fluor 555 (Life Technologies, A-21424)/goat anti-mouse Cy3 (GE Healthcare Life Sciences, PA43002, Uppsala, Sweden) antibodies, diluted in blocking solution $(1: 200)$ and simultaneously applied to the slides for $60 \mathrm{~min}$ at $37^{\circ} \mathrm{C}$ in the humidified chamber. The slides were then washed thrice with PBS for 15 min each supplemented with $0.5 \%$ Tween 20 at $43{ }^{\circ} \mathrm{C}$ in the shaking bath, rinsed in PBS and distilled water, dehydrated in the ethanol series (70, 80, and 96\%), and mounted in DAPI-containing Vectashield antifade (Vector Laboratories, $\mathrm{H}-1200$, Burlingame, CA, USA).

\section{Image acquisition and analysis}

Fluorescence images were acquired using a Leica DMLS microscope with a Leica DFC320 camera and with the Leica DFC Twain software (for QFH/AcD banded chromosomes), and using a Leica DM 2500 microscope with a Leica DFC345 FX camera and with the Leica Application SuiteV.3.8.0 software (for immunostained and DAPI-stained chromosomes and spermatozoa). The individual images were processed with Adobe Photoshop CS3. The evaluation of $5 \mathrm{hmC}$ and $5 \mathrm{mC}$ fluorescence intensity of parental chromosome sets at the zygote stage was performed by the Image J $1.48 \mathrm{v}$ software. The intensity of fluorescent signal was measured for each chromosome in a set. Then, the total fluorescence intensity in relation to the total chromosome area was calculated for each chromosome set. For the quantification of $5 \mathrm{hmC}$ and $5 \mathrm{mC}$ fluorescence intensity, the calculation of the relative values was performed: in each zygote, the value from the chromosome set with the darkest signal was set at $100 \%$, and the fluorescence intensity of the other sets was compared to it. The comparison of $5 \mathrm{hmC}$ and $5 \mathrm{mC}$ relative fluorescence intensity between the parental chromosome sets was performed in GraphPad Prism 6.01 using the Mann-Whitney $U$ test. For the assessment of the specificity of $5 \mathrm{hmC}$ and $5 \mathrm{mC}$ distribution across metaphase chromosome arms, the plot profiles of QFH, $5 \mathrm{hmC}$, and $5 \mathrm{mC}$ fluorescence intensity were built using measurements obtained in Image J $1.48 \mathrm{v}$ by the 'segmented line' instrument.

\section{Results}

We have investigated the presence of $5 \mathrm{hmC}$ in the sets of parental chromosomes, individual chromosomes, and chromosome bands in human preimplantation development. Using indirect immunofluorescence with specific antibodies, we analyzed 5hmC localization and its co-distribution with $5 \mathrm{mC}$ on the QFH-banded metaphase chromosomes of zygotes and cleavage-stage embryos. As normal diploid zygotes and embryos were not available, we performed our study on triploid ones. The developmental potential of triploid human embryos is confirmed by their capacity for implantation and even a full-term development (Gardner et al. 2011). Chen et al. (2010) have reported no difference in the DNA methylation patterns between tripronuclear and
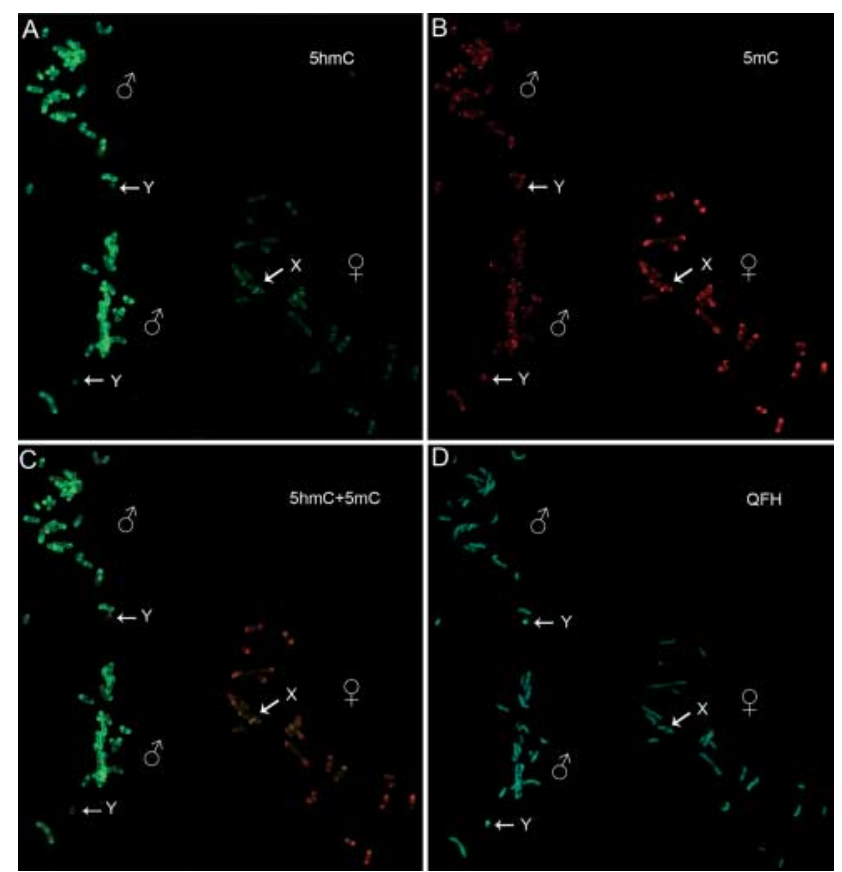

Figure 1 Immunostaining for 5-hydroxymethylcytosine (5hmC) (A), 5-methylcytosine (5mC) (B), merge image (C), and QFH banding (D) of a maternal ( $(+)$ and two paternal $\left({ }^{*}\right)$ chromosome sets of a triploid human zygote. Two paternal chromosome sets identified by the presence of $\mathrm{Y}$ chromosomes are highly hydroxymethylated and contain little $5 \mathrm{mC}$. The maternal chromosome set has a low level of $5 \mathrm{hmC}$ and is heavily methylated. QFH/AcD staining was performed before the immunodetection of $5 \mathrm{hmC}$ and $5 \mathrm{mC}$ for chromosome banding and identification. 


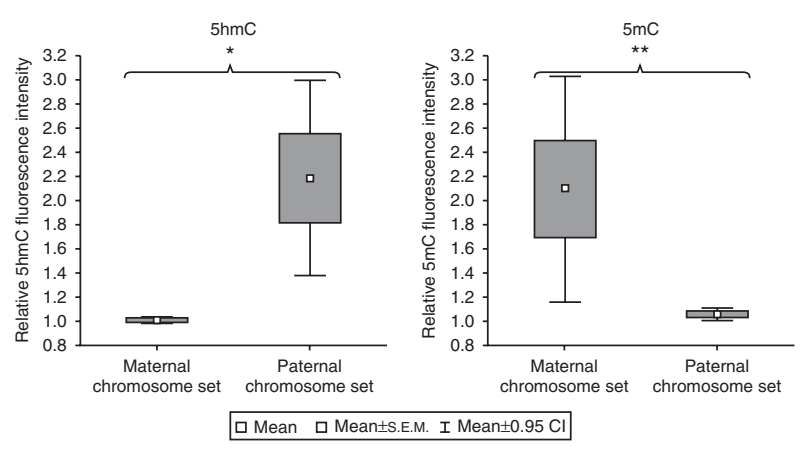

Figure 2 Box-and-whisker plots of relative fluorescence intensity for 5 -hydroxymethylcytosine $(5 \mathrm{hmC})$ and 5 -methylcytosine $(5 \mathrm{mC})$ in the maternal and paternal chromosome sets of triploid human zygotes. The relative $5 \mathrm{hmC}$ fluorescence intensity is significantly higher in paternal chromosome sets than in maternal ones $\left({ }^{*} P<0.0001\right.$, the Mann-Whitney $U$ test), whereas the relative $5 \mathrm{mC}$ fluorescence intensity is significantly higher in maternal chromosome sets than in paternal ones $(* * P<0.0001$, the Mann-Whitney $U$ test).

microsurgically corrected bipronuclear human zygotes. A case of a normal birth after microsurgical enucleation of the extrapaternal pronucleus from tripronucleate human zygote (Kattera \& Chen 2003) provides further evidence that the genome-wide steps of epigenetic reprogramming in triploid embryos could be similar or identical to those in normal ones.

To detect whether $5 \mathrm{hmC}$ patterns differ between the parental genomes in tripronucleate zygotes, we compared chromosomes of different parental origins. In seven out of 20 fixed triploid zygotes, parental chromosomes were visible as separate haploid sets (Fig. 1). In six of these zygotes, two sets demonstrated equally high hydroxymethylation in contrast to the other one, which was poorly hydroxymethylated (Fig. 1). In one zygote, one set was highly hydroxymethylated, while the two others had equally low hydroxymethylation.

The detection of chromosome $\mathrm{Y}$ is the most reliable criterion to identify the origin of parental chromosome set in human zygotes, although it allows identification of only approximately half of the genomes of male origin. It can be achieved by FISH, when studying zygotes at the pronuclear stage (Xu et al. 2005) or by chromosome banding techniques, when studying zygotic parental chromosome sets. Other criteria reported by some authors, including slightly larger size of the human paternal pronuclei and their location further away from the polar body than the maternal pronuclei (Rawlins et al. 1988, Palermo et al. 1994), have not been proved to be highly reliable (Kattera \& Chen 2003).

We analyzed the number and structure of metaphase chromosomes in seven triploid zygotes with three maternally and paternally derived separate chromosome sets in each zygote (totally 21 chromosome sets). Among 21 parental chromosome sets, eight sets were poorly hydroxymethylated and 13 sets were highly hydroxymethylated. In all eight poorly hydroxymethylated sets, X chromosome was detected. In four out of 13 highly hydroxymethylated sets, $\mathrm{X}$ chromosome was detected, while in the remaining nine, $\mathrm{Y}$ chromosome was detected, confirming that the chromosomes with a high level of $5 \mathrm{hmC}$ are of paternal origin (Fig. 1).

In 13 out of 20 fixed triploid zygotes, chromosomes were close to each other, making the identification of the whole parental chromosome sets impossible. Homologous chromosomes in all the triads differed in hydroxymethylation intensity: two homologues had equal anti-5hmC fluorescence, while the third one had higher fluorescence in three zygotes and lower fluorescence in ten zygotes. The $5 \mathrm{mC}$ patterns were inverse to those of 5hmC: highly hydroxymethylated chromosomes contained little $5 \mathrm{mC}$, while chromosomes with low levels of $5 \mathrm{hmC}$ were heavily methylated. The MannWhitney $U$ test showed statistically significant difference between the parental chromosome sets in both anti5hmC $(P<0.0001)$ and anti-5mC $(P<0.0001)$ relative fluorescence intensity (Fig. 2). Low DNA methylation level of the highly hydroxymethylated chromosome sets also indicates that these sets are of paternal origin, as hypomethylation of the paternal genome in human zygotes has been repeatedly shown by other authors using immunofluorescence approach (Beaujean et al. 2004, Fulka et al. 2004, Xu et al. 2005, Pendina et al. 2011, Guo et al. 2014b). Thus, at the zygote stage, the chromosomes of both parental genomes contain $5 \mathrm{hmC}$,
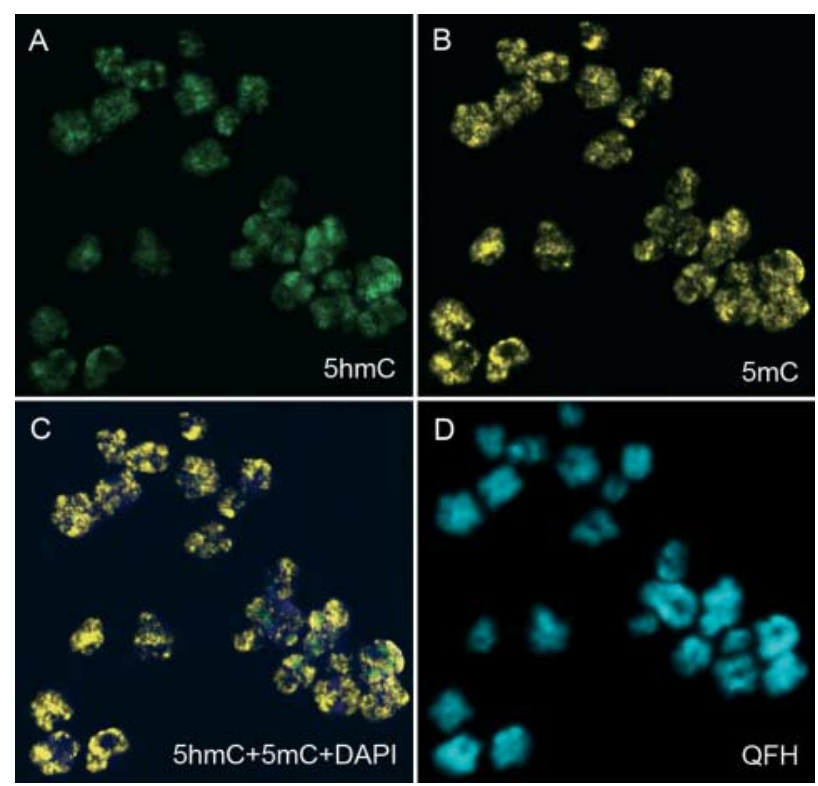

Figure 3 Immunostaining for 5-hydroxymethylcytosine (5hmC) (A), 5-methylcytosine ( $5 \mathrm{mC}$ ) (B), merge image (C), and QFH banding (D) of the chromosomes from a human oocyte. Chromosomes have readily detectable $5 \mathrm{hmC}$ and $5 \mathrm{mC}$ staining across euchromatic arms, but not in pericentric regions. QFH/AcD staining was performed before the immunodetection of $5 \mathrm{hmC}$ and $5 \mathrm{mC}$ for chromosome banding and identification. 

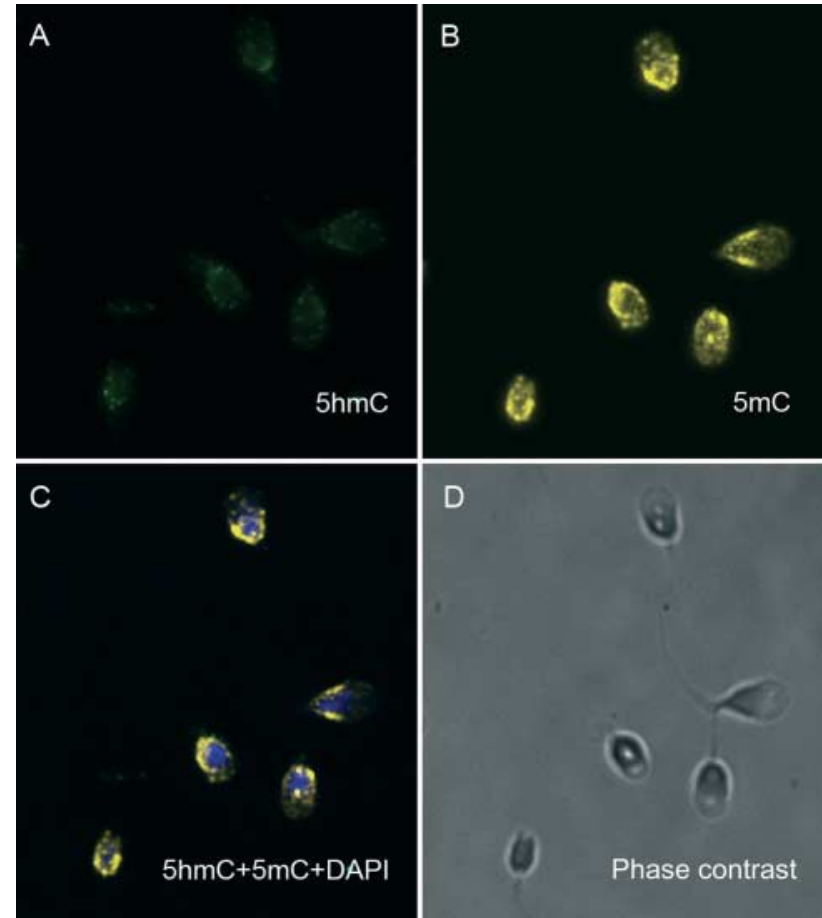

Figure 4 Immunostaining for 5-hydroxymethylcytosine (5hmC) (A), 5 -methylcytosine $(5 \mathrm{mC})(\mathrm{B})$, merge image $(\mathrm{C})$, and phase-contrast image (D) of human spermatozoa. Spermatozoa demonstrate weak hydroxymethylation and strong DNA methylation.

but the paternal genome is more hydroxymethylated than the maternal one.

We assumed that the zygotic $5 \mathrm{hmC}$ and $5 \mathrm{mC}$ patterns can be either acquired from gametes or formed de novo after fertilization. We examined DNA hydroxymethylation and methylation patterns of parental genomes in gametes. In oocytes, chromosomes had readily detectable $5 \mathrm{hmC}$ and $5 \mathrm{mC}$ staining across euchromatic arms. Pericentric regions of all chromosomes contained neither $5 \mathrm{hmC}$ nor $5 \mathrm{mC}$ (Fig. 3). In sperm, hydroxymethylation was weakly pronounced, whereas anti-5mC fluorescent signal was strong (Fig. 4). Thus, parental gamete-specific $5 \mathrm{hmC}$ and $5 \mathrm{mC}$ patterns differ from those of maternal and paternal chromosome sets in zygote. This advocates for de novo onset of hydroxymethylation and methylation patterns in the newly formed zygotic genome.

To determine where major hydroxymethylation events occur in the zygotic genome, we analyzed the $5 \mathrm{hmC}$ patterns at the level of chromosome bands. $5 \mathrm{hmC}$ accumulated in the QFH/AcD-negative chromosome regions (R-bands), avoiding the QFH/AcD-positive regions (G- and C-bands), which were poorly or non-hydroxymethylated (Fig. 5). The strongest hydroxymethylation was detected in T-bands - the subset of R-bands, which is characterized by the highest GC enrichment and the highest gene density. In both parental chromosome sets, $5 \mathrm{hmC}$ pattern featured distinct borders that corresponded to the R/G-band boundaries, making each chromosome easily recognizable by its hydroxymethylation pattern. However, in the poorly hydroxymethylated chromosome sets, some $5 \mathrm{hmC}$ bands were less pronounced due to the overall decrease in anti-5hmC fluorescence. The pericentric regions of all chromosomes including the largest heterochromatic blocks 1q12, 9q12, 16q11.2, and Yq12 contained no 5hmC, irrespective of their size (Fig. 5). When analyzing DNA methylation in the same chromosomes, in highly hydroxymethylated (paternal) sets, we detected almost homogeneous distribution
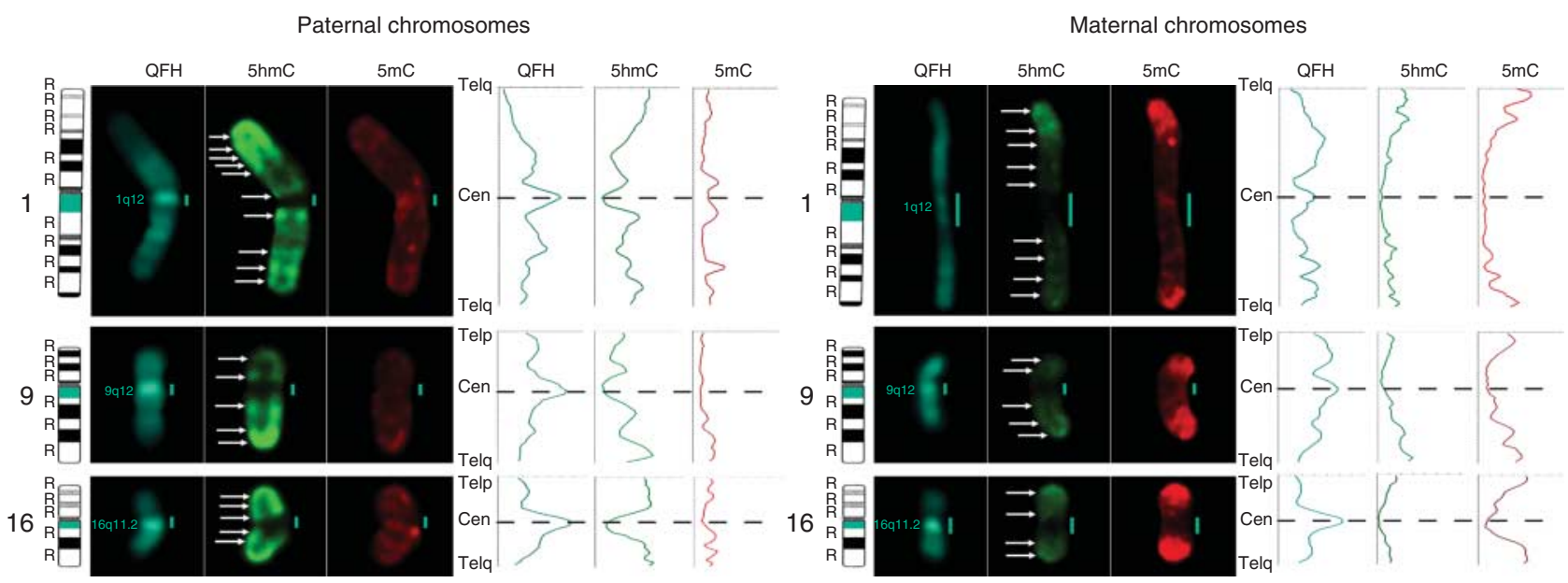

Figure 5 QFH banding (QFH) and immunostaining for 5-hydroxymethylcytosine (5hmC) and 5-methylcytosine (5mC) of human zygotic metaphase chromosomes 1, 9, and 16 from paternal and maternal chromosome sets. The distribution of hydroxymethylated DNA across the euchromatic chromosome arms is highly band specific in both parental chromosome sets: hydroxymethylated loci correspond to R-bands (indicated by arrows), but not G-bands, and have well-defined borders, which coincide with the R/G-band boundaries. The distribution of methylated DNA across the euchromatic chromosome arms is less band specific: the tendency for R-band-specific accumulation of $5 \mathrm{mC}$ is more pronounced only in maternal chromosomes, while $5 \mathrm{mC}$ is almost homogeneously distributed with a higher level of methylation only in the telomeric regions in paternal chromosomes. The heterochromatic regions 1q12, 9q12, and 16q11.2 (marked with blue) contain little 5mC and no 5hmC. 
of $5 \mathrm{mC}$ in the euchromatic arms, with a higher level of methylation only in the telomeric regions. In poorly hydroxymethylated (maternal) sets, the tendency to R-band-specific accumulation of $5 \mathrm{mC}$ was more pronounced (Fig. 5). All pericentric regions including $1 q 12,9 q 12$, and $16 q 11.2$ were poorly methylated or contained no $5 \mathrm{mC}$ at all in both parental sets (Fig. 5). Thus, the distribution of both $5 \mathrm{hmC}$ and $5 \mathrm{mC}$ is mostly confined to the euchromatic arms of zygotic chromosomes, and the chromosome pattern of $5 \mathrm{hmC}$ is distinguished from that of $5 \mathrm{mC}$ by its distinct specificity to R-bands.
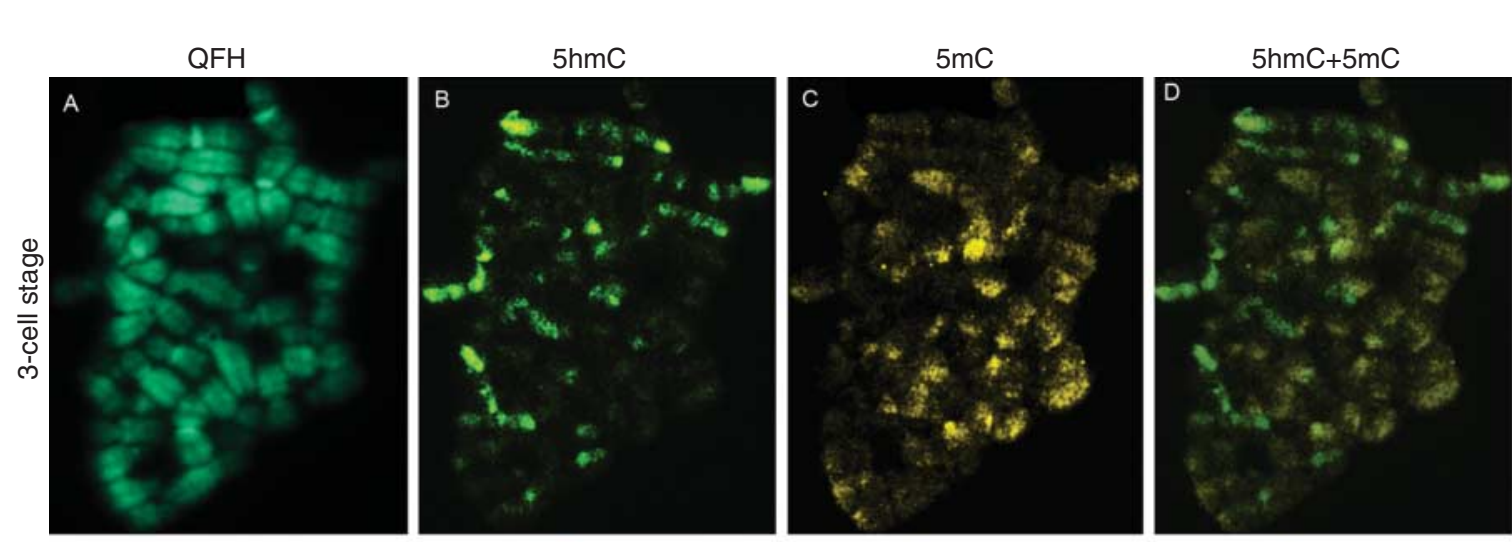

Individual
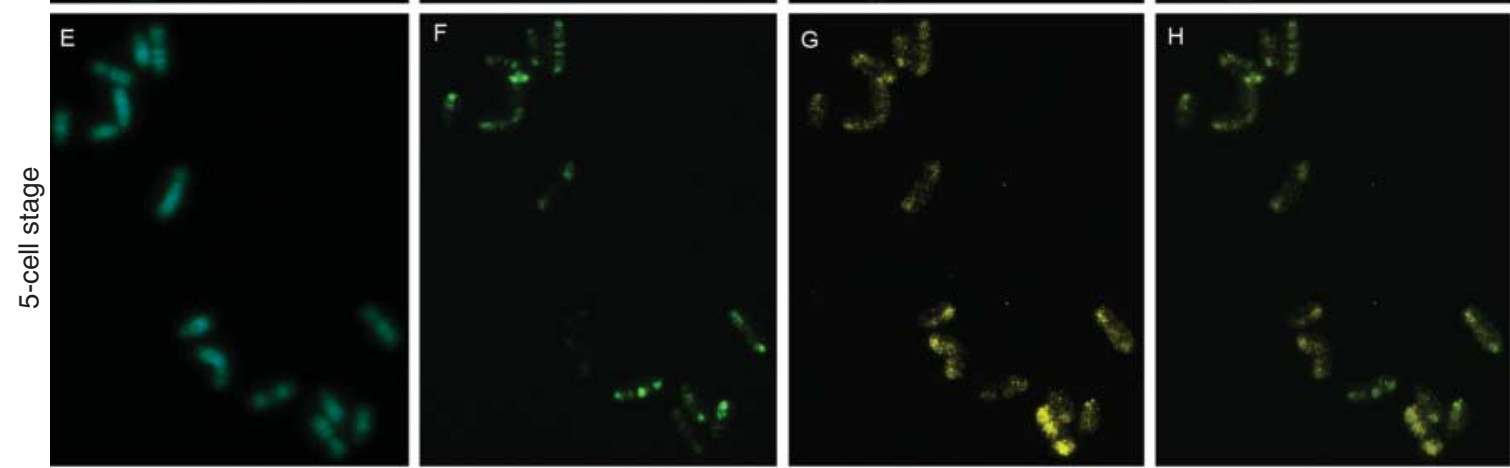
chromosomes
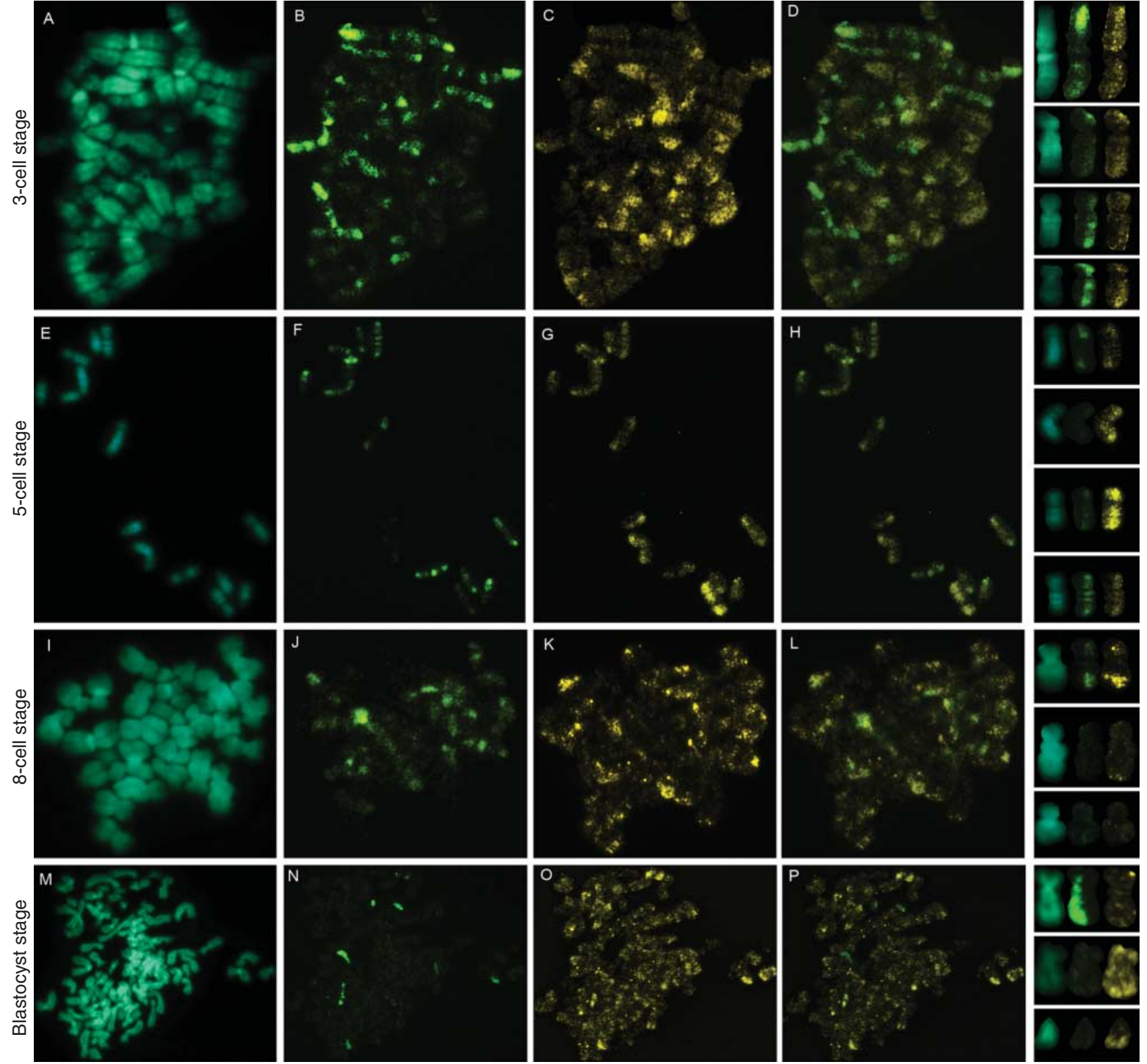

Figure 6 QFH banding (QFH) (A, E, I, and M), immunostaining for 5-hydroxymethylcytosine (5hmC) (B, F, J, and N), 5-methylcytosine (5mC) (C, G, K, and $\mathrm{O})$, and merge images $(\mathrm{D}, \mathrm{H}, \mathrm{L}$, and $\mathrm{P})$ of human metaphase chromosomes from the blastomeres of a 3-cell embryo (A, B, C, and D), a 5-cell embryo (E, F, G, and $\mathrm{H}$ ), an 8-cell embryo (I, J, K, and L), and a blastocyst ( $\mathrm{M}, \mathrm{N}, \mathrm{O}$, and $\mathrm{P}$ ). The chromosomes with asymmetrical hydroxymethylation of sister chromatids and totally unhydroxymethylated chromosomes are present in cleavage-stage embryos. The chromosome pattern of $5 \mathrm{hmC}$ coincides with that of $5 \mathrm{mC}$ : hydroxymethylated chromatids are also marked with $5 \mathrm{mC}$, while non-hydroxymethylated chromatids are poorly methylated. At the blastocyst stage, rare chromosomes with asymmetrical hydroxymethylation are still present, but the $5 \mathrm{mC}$ asymmetry is less pronounced due to acquisition by the chromosomes of a new methylation pattern, in which hypomethylated chromatids are almost absent (for details, see Pendina et al. (2011)). QFH/AcD staining was performed before the $5 \mathrm{hmC}$ and $5 \mathrm{mC}$ immunodetection for chromosome banding and identification. 
Table 1 The relative number of asymmetrically hydroxymethylated and asymmetrically methylated chromosomes in human oocytes, zygotes, and preimplantation embryos.

\begin{tabular}{lccccc}
\hline Developmental stage & $\begin{array}{c}\text { Number of } \\
\text { samples }\end{array}$ & $\begin{array}{c}\text { Number of } \\
\text { metaphases and } \\
\text { metaphase fragments }\end{array}$ & $\begin{array}{c}\text { Number of } \\
\text { chromosomes }\end{array}$ & \multicolumn{2}{c}{$\begin{array}{c}\text { Relative number of asymmetrical } \\
\text { chromosomes per developmental stage }\end{array}$} \\
\cline { 3 - 6 } & 19 & 19 & 486 & 0 & 0 \\
Oocyte & 20 & 20 & 669 & 0 & Hydroxymethylated \\
Zygote & 4 & 4 & 123 & $76.4 \pm 3.8 \%$ & $59.2 \pm 4.5 \%$ \\
3-cell & 5 & 10 & 275 & $40.7 \pm 2.9 \%$ & $33.4 \pm 2.9 \%$ \\
4-5-cell & 15 & 16 & 368 & $14.2 \pm 2.0 \%$ & $17.3 \pm 1.2 \%$ \\
7-cell-morula & 37 & 65 & 2271 & $6.5 \pm 0.5 \%$ & $6.6 \pm 0.5 \%$ \\
Blastocyst & & &
\end{tabular}

To check whether $5 \mathrm{hmC}$ is maintained in human preimplantation development, we analyzed chromosome hydroxymethylation patterns at the subsequent cleavage divisions up to and including the blastocyst stage. The zygotic $5 \mathrm{hmC}$ pattern was not present any more. We observed chromosomes with asymmetrical $5 \mathrm{hmC}$ distribution in sister chromatids - hemihydroxymethylated chromosomes (Fig. 6). The hydroxymethylated chromatids maintained band-specific $5 \mathrm{hmC}$ distribution, as it appeared at the zygote stage. In some chromosomes, hydroxymethylated and non-hydroxymethylated regions alternated in the chromatids demarcating sister chromatid exchanges. Along with asymmetrically stained chromosomes, we detected the chromosomes with equally poor, if any, hydroxymethylation in both chromatids (Fig. 6). Notably, the chromosome pattern of $5 \mathrm{hmC}$ coincided with that of $5 \mathrm{mC}$ : hydroxymethylated chromatids retained the zygotic $5 \mathrm{mC}$ pattern, while non-hydroxymethylated chromatids were poorly methylated. At the blastocyst stage, asymmetrical hydroxymethylation was still present in rare chromosomes, but the methylation asymmetry was less pronounced due to acquisition of a new chromosome methylation pattern, in which hypomethylated chromatids were almost absent (described in detail in our previous study Pendina et al. (2011)) (Fig. 6). We counted the asymmetrically hydroxymethylated chromosomes in total metaphases and metaphase fragments of the analyzed embryos per developmental stage. At the 3 -cell stage, $76.4 \pm 3.8 \%$ of chromosomes featured asymmetrical $5 \mathrm{hmC}$ distribution in sister chromatids. At cleavages, from the 4-cell stage to the blastocyst stage, the number of asymmetrically hydroxymethylated chromosomes decreased. They amounted to $40.7 \pm 2.9 \%$ at the $4-5$-cell stage, $14.2 \pm 2.0 \%$ at the 7 -cell-morula stage, and $6.5 \pm 0.5 \%$ at the blastocyst stage, while the remaining chromosomes were unhydroxymethylated (Table 1). The relative number of asymmetrically methylated chromosomes was more or less equal to that of asymmetrically hydroxymethylated chromosomes and amounted to $59.2 \pm 4.5 \%$ at the 3 -cell stage, $33.4 \pm 2.9 \%$ at the $4-5$-cell stage, $17.3 \pm 1.2 \%$ at the 7 -cell-morula stage, and $6.6 \pm 0.5 \%$ at the blastocyst stage (Table 1). Hence, cleavage divisions in human preimplantation development are accompanied with a decrease in both $5 \mathrm{hmC}$ and $5 \mathrm{mC}$ levels.

\section{Discussion}

We have analyzed 5hmC patterns during DNA methylation reprogramming in human preimplantation development. We based our experimental approach on the detection of $5 \mathrm{hmC}$ and $5 \mathrm{mC}$ in preparations of zygotic and embryonic metaphase chromosomes using highly specific antibodies. This method provides information on hydroxymethylation and methylation patterns on the largest scale of genomic organization with a resolution at the level of individual chromosomes and chromosome bands.

We show that chromosomes of human zygotes have unique $5 \mathrm{hmC}$ and $5 \mathrm{mC}$ patterns, which differ from those in parental gametes. The zygotic patterns are characterized by inverse $5 \mathrm{hmC}$ and $5 \mathrm{mC}$ levels: highly hydroxymethylated paternal chromosomes contain little $5 \mathrm{mC}$, while maternal chromosomes have low levels of $5 \mathrm{hmC}$ and are heavily methylated (Figs 1 and 2). The inverse $5 \mathrm{hmC}$ and $5 \mathrm{mC}$ patterns can be explained by conversion of $5 \mathrm{mC}$ to $5 \mathrm{hmC}$ in the paternal genome after fertilization; in contrast, the maternal genome avoids massive conversion of methyl to hydroxymethyl groups and remains highly methylated. Our observations are in line with studies demonstrating inverse $5 \mathrm{mC}$ and $5 \mathrm{hmC}$ patterns in the parental pronuclei of non-human mammals (Iqbal et al. 2011, Wossidlo et al. 2011, Salvaing et al. 2012, Zhang et al. 2012). An intensive decrease in DNA methylation in the paternal genome in a shared cytoplasm is suggested to be a part of chromatin remodeling with the purpose of providing unrestricted access to common cytoplasmic factors for both parental genomes in a zygote (Dean 2014).

It has long been believed that in mammalian preimplantation development, parental genomes are demethylated through different pathways: maternal genome is exclusively demethylated through a replicationdependent (passive) mechanism during cleavage divisions, while paternal genome undergoes global replication-independent (active) loss of methyl groups at the zygote stage and then is also demethylated passively (Rougier et al. 1998, Reik et al. 2001, 
Inoue \& Zhang 2011, Pendina et al. 2011). However, a number of studies have demonstrated that replicationdependent and -independent (through TET3-mediated oxidation of $5 \mathrm{mC}$ to $5 \mathrm{hmC}$ ) demethylation mechanisms coexist in both male and female pronuclei of mouse zygotes (Salvaing et al. 2012, Guo et al. 2014a, Shen et al. 2014, Wang et al. 2014). In the human zygotes at the pronuclear stage, hydroxymethylation of both male and female pronuclei with lower immunofluorescent signal in female pronuclei has been reported by Guo et al. (2014b). Our results indicate that maternal chromosomes in human zygotes have low but readily detectable hydroxymethylation, which coexists with the high level of methylation. Hydroxymethylation pattern of maternal chromosomes can either, at least in part, come from oocyte or be a result of selective conversion of $5 \mathrm{mC}$ to $5 \mathrm{hmC}$ at the zygote stage. To shed light on the involvement of parent-specific $5 \mathrm{mC}$-to- $5 \mathrm{hmC}$ conversion in the genome reprogramming in human zygotes, experiments on expression, translation, and binding of TET enzymes in human gametes and embryos are needed.

The genome of human zygotes appears to be hydroxymethylated selectively. Genome regions with high accumulation of $5 \mathrm{hmC}$ coincide with cytogenetically detected R-bands (Figs 1 and 5). The R-band-specific hydroxymethylation is most pronounced in paternal chromosomes. The amount of $5 \mathrm{hmC}$ in the R-bands of maternal chromosomes is reduced but readily detectable. Irrespective of parental origin, hydroxymethylated regions have well-defined borders, which strictly correspond to the R/G-band boundaries (Fig. 5). The specificity of hydroxymethylation to R-bands is probably associated with their structural and functional properties. In contrast to G-bands, R-bands are enriched in CpG dinucleotides DNA methylation, and thus, hydroxymethylation sites. GC enrichment positively correlates with gene density and 'open' chromatin structure (Holmquist \& Ashley 2006). It has been previously suggested that there may be distinct demarcation between 'open' and 'closed' chromatin (Gilbert et al. 2004). R/G-band transition is also important for the early/late replication switch between transcribed and silenced regions (Watanabe \& Maekawa 2013). Hence, the sharp transitions between hydroxymethylated and non-hydroxymethylated DNAs at the R/G-band boundaries may contribute to the marking of structural/functional genome 'units' corresponding to chromosome bands in the newly formed genome of a zygote. Our observations support the hypothesis of a dual function of $5 \mathrm{hmC}$ : as an intermediate product in the TET-mediated DNA demethylation pathway, and as an epigenetic modification with a role of its own (Branco et al. 2011, Ficz et al. 2011, Salvaing et al. 2012, Li \& O'Neill 2013).

In the view of epigenetic marking of genome 'units' within chromosomes, the establishment of heterochromatin signatures is of special interest. In human zygotes, the largest heterochromatic regions $1 q 12,9 q 12$, $16 q 11.2$, and $\mathrm{Yq} 12$ contain little or no $5 \mathrm{mC}$, which is in line with our previous observations (Baranov et al. 2005, Pendina et al. 2011). In contrast, in the somatic cells of adults and fetuses, the constitutive heterochromatin is hallmarked by a high level of DNA methylation (Barbin et al. 1994, Montpellier et al. 1994, Kokalj-Vokac et al. 1998, Pendina et al. 2005, 2011, Pfarr et al. 2005). It can therefore be expected that heterochromatic regions in zygotes are enriched in $5 \mathrm{hmC}$, an active demethylation intermediate. However, in the studied zygotes, heterochromatic regions $1 q 12,9 q 12$, 16q11.2, and $Y q 12$ appear to be completely unhydroxymethylated in both parental genomes (Figs 1 and 5). Moreover, both $5 \mathrm{mC}$ and $5 \mathrm{hmC}$ are absent in the heterochromatic regions of the oocyte chromosomes. Our data suggest that DNA methylation reprogramming of euchromatic and heterochromatic regions in the genome of human zygote proceeds in a different manner, favoring a specific function of heterochromatin during preimplantation period.

At cleavages, chromosome $5 \mathrm{hmC}$ pattern changes dramatically with each division. Chromosomes with one non-hydroxymethylated and one hydroxymethylated chromatid appear. Such asymmetrical (or hemihydroxymethylated) chromosomes are present at all cleavage stages up to and including the blastocyst stage (Fig. 6). The zygotically derived level and pattern of $5 \mathrm{hmC}$ are intact only in one - hydroxymethylated - chromatid throughout cleavages and are not reproduced in its sister chromatid. At cleavages, chromatids with zygotic $5 \mathrm{hmC}$ signatures are distributed among blastomeres. With each division, the relative number of hemihydroxymethylated chromosomes decreases, whereas chromosomes with both non-hydroxymethylated chromatids become numerous. These result in a gradual decrease in the total genome hydroxymethylation level during cleavages. Our findings point toward passive (replication-dependent) loss of $5 \mathrm{hmC}$, when $5 \mathrm{hmC}$ pattern is not reproduced in the newly synthesized DNA strands. The replicationdependent loss of $5 \mathrm{hmC}$ has been reported in mice (Inoue \& Zhang 2011), suggesting that this mechanism is involved in the reprogramming in both human and mouse preimplantation embryos.

The passive loss of $5 \mathrm{hmC}$ in human cleavage-stage embryos coincides with that of $5 \mathrm{mC}$. The chromosome patterns of $5 \mathrm{mC}$ passive loss have been previously reported in human (Pendina et al. 2011) and mouse (Rougier et al. 1998) preimplantation embryos and correlate with those observed in our study. The coincidence of $5 \mathrm{hmC}$ and $5 \mathrm{mC}$ in some chromatids or chromatid regions is explained by the permanent persistence of their patterns in these loci throughout all cleavages starting from the zygote stage. Notably, this unique fate of the chromatids with zygotic epigenetic signatures can be observed at cleavages only when studying metaphase chromosomes. The interphase 
immunofluorescent studies reported only a gradual decrease in general $5 \mathrm{mC}$ level in human preimplantation development (Beaujean et al. 2004, Fulka et al. 2004, Santos et al. 2010), as the discreteness of chromosome epigenetic marking could not be detected due to chromatin decondensation.

In contrast to the R-band-specific hydroxymethylation at the zygote stage, which is most probably associated with conversion of $5 \mathrm{mC}$ to $5 \mathrm{hmC}$, the passive loss of both $5 \mathrm{hmC}$ and $5 \mathrm{mC}$ is not selective and equally involves all bands of all chromosomes. The decrease in the number of asymmetrically hydroxymethylated chromosomes indicates that there are no new global hydroxymethylation events during cleavage divisions. The absence of global hydroxymethylation does not contradict the possibility of local hydroxymethylation at specific genome regions to provide tight epigenetic regulation of the embryonic genome. The rare hemihydroxymethylated chromosomes at the blastocyst stage are quite intriguing. It is obvious that the presence of such chromosomes is compatible with the DNA remethylation and the primary differentiation of blastomeres to the inner cell mass and the trophectoderm. The further fate and the biological role of the chromatids with zygotic $5 \mathrm{hmC}$ signatures is an open and very interesting question. Thus, the DNA methylation reprogramming in human preimplantation development is likely to include at least three mechanisms: at the zygote stage, R-band-specific conversion of $5 \mathrm{mC}$ to $5 \mathrm{hmC}$, which is strongly pronounced in the paternal genome and, at subsequent cleavages, replication-dependent non-specific loss of $5 \mathrm{hmC}$ and $5 \mathrm{mC}$ from both maternal and paternal genomes.

In conclusion, the $5 \mathrm{hmC}$ pattern is dynamically changed during the reprogramming of DNA methylation in human zygotes and cleavage-stage embryos. At the zygote stage, the genome-wide hydroxymethylation is strongly pronounced in the paternal genome. The global $5 \mathrm{hmC}$ pattern in zygotes is composed of local hydroxymethylation events, which are confined to the cytogenetically defined chromosome regions - R-bands. The transitions of hydroxymethylated to non-hydroxymethylated DNA at the R/G-band boundaries may contribute to the marking of structural/functional genome 'units' corresponding to chromosome bands in the newly formed genome of a zygote. The selective hydroxymethylation at the zygote stage can be treated as a new characteristic of R-bands distinguishing them from G-bands, in addition to the known differences in replication timing, GC enrichment, and gene density. At cleavages, there are no new global hydroxymethylation events and the genome-wide loss of $5 \mathrm{mC}$ and $5 \mathrm{hmC}$ proceeds through a non-selective passive mechanism. We believe that our conclusions are essential to expand knowledge of the initial stages of human embryogenesis and will have value both for fundamental and practical aspects of human reproduction science.

\section{Declaration of interest}

The authors declare that there is no conflict of interest that could be perceived as prejudicing the impartiality of the research reported.

\section{Funding}

This work was supported by the Russian Scientific Foundation (grant number 14-15-00737). O A Efimova and E M Shilnikova were personally supported by scholarship from RF President and Administration of St Petersburg.

\section{Author contribution statement}

O A Efimova, A A Pendina, A V Tikhonov, and I D Fedorova contributed equally to this work.

\section{Acknowledgements}

The authors are grateful to Ksenia O Khudadyan for helpful advice during preparation of the manuscript.

\section{References}

Abdalla H, Yoshizawa Y \& Hochi S 2009 Active demethylation of paternal genome in mammalian zygotes. Journal of Reproduction and Development 55 356-360. (doi:10.1262/jrd.20234)

Baranov VS, Pendina AA, Kuznetsova TV, Efimova OA, Fedorova ID, Leont'eva OA, Korsak VS \& Nikol'skiì NN 2005 Peculiarities of metaphase chromosome methylation pattern in preimplantation human embryos. Tsitologiia 47 723-730. Russian.

Barbin A, Montpellier C, Kokalj-Vokac N, Gibaud A, Niveleau A, Malfoy B, Dutrillaux B \& Bourgeois CA 1994 New sites of methylcytosine-rich DNA detected on metaphase chromosomes. Human Genetics 94 684-692. (doi:10.1007/BF00206964)

Beaujean N, Hartshorne G, Cavilla J, Taylor J, Gardner J, Wilmut I, Meehan R \& Young L 2004 Non-conservation of mammalian preimplantation methylation dynamics. Current Biology 14 R266-R267. (doi:10.1016/j.cub.2004.03.019)

Bird A 2002 DNA methylation patterns and epigenetic memory. Genes and Development 16 6-21. (doi:10.1101/gad.947102)

Bonder MJ, Kasela S, Kals M, Tamm R, Lokk K, Barragan I, Buurman WA, Deelen P, Greve JW, Ivanov M et al. 2014 Genetic and epigenetic regulation of gene expression in fetal and adult human livers. BMC Genomics 15 860. (doi:10.1186/1471-2164-15-860)

Branco MR, Ficz G \& Reik W 2011 Uncovering the role of 5 -hydroxymethylcytosine in the epigenome. Nature Reviews. Genetics 13 7-13. (doi:10.1038/nrn3125) (doi:10.1038/nrn3125)

Byun HM, Siegmund KD, Pan F, Weisenberger DJ, Kanel G, Laird PW \& Yang AS 2009 Epigenetic profiling of somatic tissues from human autopsy specimens identifies tissue- and individual-specific DNA methylation patterns. Human Molecular Genetics 18 4808-4817. (doi:10.1093/hmg/ ddp445)

Cao Z, Zhou N, Zhang Y, Zhang Y, Wu R, Li Y, Zhang Y \& Li N 2014 Dynamic reprogramming of 5-hydroxymethylcytosine during early porcine embryogenesis. Theriogenology 81 496-508. (doi:10.1016/j. theriogenology.2013.10.025)

Chen X, Fan Y, Long X \& Sun X 2010 Similar DNA methylation and histone H3 lysine 9 dimethylation patterns in tripronuclear and corrected bipronuclear human zygotes. Journal of Reproduction and Development 56 324-329. (doi:10.1262/jrd.09-170A)

Craig JM \& Bickmore WA 1994 The distribution of CpG islands in mammalian chromosomes. Nature Genetics 7 376-382. (doi:10.1038/ ng0794-376) (doi:10.1038/ng0794-376) 
Dean W 2014 DNA methylation and demethylation: a pathway to gametogenesis and development. Molecular Reproduction and Development 81 113-125. (doi:10.1002/mrd.22280)

Doerfler W 1981 DNA methylation - a regulatory signal in eukaryotic gene expression. Journal of General Virology 57 1-20. (doi:10.1099/ 0022-1317-57-1-1)

Ehrlich M \& Lacey M 2013 DNA hypomethylation and hemimethylation in cancer. Advances in Experimental Medicine and Biology 754 31-56. (doi:10.1007/978-1-4419-9967-2_2)

Ficz G, Branco MR, Seisenberger S, Santos F, Krueger F, Hore TA, Marques CJ, Andrews S \& Reik W 2011 Dynamic regulation of 5-hydroxymethylcytosine in mouse ES cells and during differentiation. Nature 473 398-402. (doi:10.1038/nature10008)

Fulka H, Mrazek M, Tepla O \& Fulka J Jr 2004 DNA methylation pattern in human zygotes and developing embryos. Reproduction 128 703-708. (doi:10.1530/rep.1.00217)

Gardner RJM, Sutherland GR \& Shaffer LG 2011 Chromosome abnormalities and genetic counseling, 4th edn. New York: Oxford University Press. (doi:10.1093/med/9780195375336.001.0001)

Gilbert N, Boyle S, Fiegler H, Woodfine K, Carter NP \& Bickmore WA 2004 Chromatin architecture of the human genome: gene-rich domains are enriched in open chromatin fibers. Cell 118 555-566. (doi:10.1016/ j.cell.2004.08.011)

Grigorian AS, Kruglyakov PV, Taminkina UA, Efimova OA, Pendina AA, Voskresenskaya AV, Kuznetsova TV \& Polyntsev DG 2010 Alterations of cytological and karyological profile of human mesenchymal stem cells during in vitro culturing. Bulletin of Experimental Biology and Medicine 150 125-130. (doi:10.1007/s10517-010-1086-x)

Guo F, Li X, Liang D, Li T, Zhu P, Guo H, Wu X, Wen L, Gu TP, Hu B et al. 2014a Active and passive demethylation of male and female pronuclear DNA in the mammalian zygote. Cell Stem Cell 15 447-458. (doi:10. 1016/j.stem.2014.08.003)

Guo H, Zhu P, Yan L, Li R, Hu B, Lian Y, Yan J, Ren X, Lin S, Li J et al. 2014 b The DNA methylation landscape of human early embryos. Nature $\mathbf{5 1 1}$ 606-610. (doi:10.1038/nature13544)

Holmquist GP \& Ashley T 2006 Chromosome organization and chromatin modification: influence on genome function and evolution. Cytogenetic and Genome Research 114 96-125. (doi:10.1159/000093326)

Inoue A \& Zhang Y 2011 Replication-dependent loss of 5-hydroxymethylcytosine in mouse preimplantation embryos. Science 334194. (doi:10.1126/science.1212483)

Iqbal K, Jin SG, Pfeifer GP \& Szabó PE 2011 Reprogramming of the paternal genome upon fertilization involves genome-wide oxidation of 5-methylcytosine. PNAS 108 3642-3647. (doi:10.1073/pnas.10140 33108)

Ito S, D'Alessio AC, Taranova OV, Hong K, Sowers LC \& Zhang Y 2010 Role of Tet proteins in $5 \mathrm{mC}$ to $5 \mathrm{hmC}$ conversion, ES-cell self-renewal and inner cell mass specification. Nature 466 1129-1133. (doi:10.1038/nature09303)

Ivanov M, Kals M, Kacevska M, Barragan I, Kasuga K, Rane A, Metspalu A, Milani L \& Ingelman-Sundberg M 2013 Ontogeny, distribution and potential roles of 5-hydroxymethylcytosine in human liver function. Genome Biology 14 R83. (doi:10.1186/gb-2013-14-8-r83)

Kafri T, Ariel M, Brandeis M, Shemer R, Urven L, McCarrey J, Cedar H \& Razin A 1992 Developmental pattern of gene-specific DNA methylation in the mouse embryo and germ line. Genes and Development 6 705-714. (doi:10.1101/gad.6.5.705)

Kafri T, Gao X \& Razin A 1993 Mechanistic aspects of genome-wide demethylation in the preimplantation mouse embryo. PNAS 90 10558-10562. (doi:10.1073/pnas.90.22.10558)

Kattera S \& Chen C 2003 Normal birth after microsurgical enucleation of tripronuclear human zygotes: case report. Human Reproduction $\mathbf{1 8}$ 1319-1322. (doi:10.1093/humrep/deg262)

Kokalj-Vokac N, Zagorac A, Pristovnik M, Bourgeois CA \& Dutrillaux B 1998 DNA methylation of the extraembryonic tissues: an in situ study on human metaphase chromosomes. Chromosome Research 6 161-166. (doi:10.1023/A:1009299331871)

Li W \& Liu M 2011 Distribution of 5-hydroxymethylcytosine in different human tissues. Journal of Nucleic Acids 2011 870726. (doi:10.4061/ 2011/870726)

Li Y \& O'Neill C 2013 5'-Methylcytosine and 5'-hydroxymethylcytosine each provide epigenetic information to the mouse zygote. PLOS ONE 8 e63689. (doi:10.1371/journal.pone.0063689)
Luo Y, Lu X \& Xie H 2014 Dynamic Alu methylation during normal development, aging, and tumorigenesis. BioMed Research International 2014 784706. (doi:10.1155/2014/784706)

Mayer W, Niveleau A, Walter J, Fundele R \& Haaf T 2000 Demethylation of the zygotic paternal genome. Nature 403 501-502. (doi:10.1038/ 35000656)

Monk M, Boubelik M \& Lehnert S 1987 Temporal and regional changes in DNA methylation in the embryonic, extraembryonic and germ cell lineages during mouse embryo development. Development 99 371-382.

Montpellier C, Burgeois CA, Kokalj-Vokac N, Muleris M, Niveleau A, Reynaud C, Gibaud A, Malfoy B \& Dutrillaux B 1994 Detection of methylcytosine-rich heterochromatin on banded chromosomes. Application to cells with various status of DNA methylation. Cancer Genetics and Cytogenetics 78 87-93. (doi:10.1016/0165-4608(94)90052-3)

Nestor CE, Ottaviano R, Reddington J, Sproul D, Reinhardt D, Dunican D, Katz E, Dixon JM, Harrison DJ \& Meehan RR 2012 Tissue type is a major modifier of the 5-hydroxymethylcytosine content of human genes. Genome Research 22 467-477. (doi:10.1101/gr.126417.111)

Palermo G, Munne S \& Cohen J 1994 The human zygote inherits its mitotic potential from the male gamete. Human Reproduction 9 1220-1225

Patkin EL 2002 Epigenetic mechanisms for primary differentiation in mammalian embryos. International Review of Cytology 216 81-129.

Pendina AA, Efimova OA, Kaminskaia AN, Kuznetsova TV \& Baranov VS 2005 Immunocytochemical analysis of human metaphase chromosome methylation status. Tsitologiia 47 731-737. Russian.

Pendina AA, Efimova OA, Fedorova ID, Leont'eva OA, Shilnikova EM, Lezhnina JG, Kuznetzova TV \& Baranov VS 2011 DNA methylation patterns of metaphase chromosomes in human preimplantation embryos. Cytogenetic and Genome Research 132 1-7. (doi:10.1159/ 000318673)

Pendina AA, Efimova OA, Chiryaeva OG, Tikhonov AV, Petrova LI, Dudkina VS, Sadik NA, Fedorova ID, Galembo IA, Kuznetzova TV et al. 2014 A comparative cytogenetic study of miscarriages after IVF and natural conception in women aged under and over 35 years. Journal of Assisted Reproduction and Genetics 31 149-155. (doi:10.1007/s10815013-0148-1)

Pfarr W, Webersinke G, Paar C \& Wechselberger C 2005 Immunodetection of $5^{\prime}$-methylcytosine on Giemsa-stained chromosomes. Biotechniques 38 527-528, 530. (doi:10.2144/05384BM01)

Pliushch G, Schneider E, Weise D, El Hajj N, Tresch A, Seidmann L, Coerdt W, Müller AM, Zechner U \& Haaf T 2010 Extreme methylation values of imprinted genes in human abortions and stillbirths. American Journal of Pathology 176 1084-1090. (doi:10.2353/ajpath.2010. 090764)

Rawlins RG, Binor Z, Radwanska E \& Dmowski WP 1988 Microsurgical enucleation of tripronuclear human zygotes. Fertility and Sterility $\mathbf{5 0}$ 266-272.

Razin A \& Cedar H 1991 DNA methylation and gene expression. Microbiological Reviews 55 451-458.

Reik W, Dean W \& Walter J 2001 Epigenetic reprogramming in mammalian development. Science 293 1089-1093. (doi:10.1126/science.1063443)

Rougier N, Bourc'his D, Gomes DM, Niveleau A, Plachot M, Pàldi A \& Viegas-Péquignot E 1998 Chromosome methylation patterns during mammalian preimplantation development. Genes and Development 12 2108-2113. (doi:10.1101/gad.12.14.2108)

Salvaing J, Aguirre-Lavin T, Boulesteix C, Lehmann G, Debey P \& Beaujean N 2012 5-Methylcytosine and 5-hydroxymethylcytosine spatiotemporal profiles in the mouse zygote. PLOS ONE 7 e38156. (doi:10.1371/journal.pone.0038156)

Santos F, Hendrich B, Reik W \& Dean W 2002 Dynamic reprogramming of DNA methylation in the early mouse embryo. Developmental Biology 241 172-182. (doi:10.1006/dbio.2001.0501)

Santos F, Hyslop L, Stojkovic P, Leary C, Murdoch A, Reik W, Stojkovic M, Herbert M \& Dean W 2010 Evaluation of epigenetic marks in human embryos derived from IVF and ICSI. Human Reproduction 25 2387-2395. (doi:10.1093/humrep/deq151)

Shen L, Inoue A, He J, Liu Y, Lu F \& Zhang Y 2014 Tet3 and DNA replication mediate demethylation of both the maternal and paternal genomes in mouse zygotes. Cell Stem Cell 15 459-470. (doi:10.1016/j.stem.2014. 09.002) 
Shi W \& Haaf T 2002 Aberrant methylation patterns at the two-cell stage as an indicator of early developmental failure. Molecular Reproduction and Development 63 329-334. (doi:10.1002/mrd.90016)

Shubina AN, Egorova AA, Baranov VS \& Kiselev AV 2013 Recent advances in gene therapy of endometriosis. Recent Patents on DNA \& Gene Sequences 7 169-178. (doi:10.2174/18722156113079990021)

Skryabin NA, Tolmacheva EN, Lebedev IN, Zavyalova MV, Slonimskaya EM \& Cherdyntseva NV 2013 Dynamics of aberrant methylation of functional groups of genes in progression of breast cancer. Molecular Biology 47 267-274. (doi:10.1134/S0026893313020131)

Stroud H, Feng S, Morey Kinney S, Pradhan S \& Jacobsen SE 2011 5-Hydroxymethylcytosine is associated with enhancers and gene bodies in human embryonic stem cells. Genome Biology 12 R54. (doi:10.1186/ gb-2011-12-6-r54)

Surani MA, Hayashi K \& Hajkova P 2007 Genetic and epigenetic regulators of pluripotency. Cell 128 747-762. (doi:10.1016/j.cell.2007.02.010)

Tahiliani M, Koh KP, Shen Y, Pastor WA, Bandukwala H, Brudno Y, Agarwal S, Iyer LM, Liu DR, Aravind L et al. 2009 Conversion of 5 -methylcytosine to 5-hydroxymethylcytosine in mammalian DNA by MLL partner TET1. Science 324 930-935. (doi:10.1126/science. 1170116)

Teif VB, Beshnova DA, Vainshtein Y, Marth C, Mallm JP, Höfer T \& Rippe K 2014 Nucleosome repositioning links DNA (de)methylation and differential CTCF binding during stem cell development. Genome Research 24 1285-1295. (doi:10.1101/gr.164418.113)

Tolmacheva EN, Kashevarova AA, Skryabin NA \& Lebedev IN 2011 DNA methylation profile in human placental tissues. Molecular Biology 45 493-499. (doi:10.1134/S0026893311030198)

Wang L, Zhang J, Duan J, Gao X, Zhu W, Lu X, Yang L, Zhang J, Li G, Ci W et al. 2014 Programming and inheritance of parental DNA methylomes in mammals. Cell 157 979-991. (doi:10.1016/j.cell.2014.04.017)

Watanabe Y \& Maekawa M 2013 R/G-band boundaries: genomic instability and human disease. Clinica Chimica Acta 419 108-112. (doi:10.1016/ j.cca.2013.02.011)

Wossidlo M, Nakamura T, Lepikhov K, Marques CJ, Zakhartchenko V, Boiani M, Arand J, Nakano T, Reik W \& Walter J 2011 5-Hydroxymethylcytosine in the mammalian zygote is linked with epigenetic reprogramming. Nature Communications 2 241. (doi:10.1038/ncomms 1240)
Wu H, D'Alessio AC, Ito S, Wang Z, Cui K, Zhao K, Sun YE \& Zhang Y 2011 Genome-wide analysis of 5-hydroxymethylcytosine distribution reveals its dual function in transcriptional regulation in mouse embryonic stem cells. Genes and Development 25 679-684. (doi:10.1101/gad.2036011)

Xu Y, Zhang JJ, Grifo JA \& Krey LC 2005 DNA methylation patterns in human tripronucleate zygotes. Molecular Human Reproduction 11 167-171. (doi:10.1093/molehr/gah145)

Yildirim O, Li R, Hung JH, Chen PB, Dong X, Ee LS, Weng Z, Rando OJ \& Fazzio TG $2011 \mathrm{Mbd} 3 / \mathrm{NURD}$ complex regulates expression of 5-hydroxymethylcytosine marked genes in embryonic stem cells. Cell 147 1498-1510. (doi:10.1016/j.cell.2011.11.054)

Zhang P, Su L, Wang Z, Zhang S, Guan J, Chen Y, Yin Y, Gao F, Tang B \& Li Z 2012 The involvement of 5-hydroxymethylcytosine in active DNA demethylation in mice. Biology of Reproduction 86 104. (doi:10.1095/ biolreprod.111.096073)

Zheleznyakova GY, Voisin S, Kiselev AV, Sällman Almén M, Xavier MJ, Maretina MA, Tishchenko LI, Fredriksson R, Baranov VS \& Schiöth HB 2013 Genome-wide analysis shows association of epigenetic changes in regulators of Rab and Rho GTPases with spinal muscular atrophy severity. European Journal of Human Genetics 21 988-993. (doi:10.1038/ejhg. 2012.293)

Zhenilo SV, Musharova OS \& Prokhorchuk EB 2013 Kaiso transcription factor does not interact with hydroxymethylated DNA in CTGCNA sequence. Molecular Biology 47 461-463. (doi:10.1134/S00268 93313030187)

Zhu J, Adli M, Zou JY, Verstappen G, Coyne M, Zhang X, Durham T, Miri M, Deshpande V, De Jager PL et al. 2013 Genome-wide chromatin state transitions associated with developmental and environmental cues. Cell 152 642-654. (doi:10.1016/j.cell.2012.12.033)

Zou X, Ma W, Solov'yov IA, Chipot C \& Schulten K 2012 Recognition of methylated DNA through methyl-CpG binding domain proteins. Nucleic Acids Research 40 2747-2758. (doi:10.1093/nar/gkr1057)

Received 6 July 2014

First decision 5 August 2014

Revised manuscript received 1 December 2014

Accepted 11 December 2014 